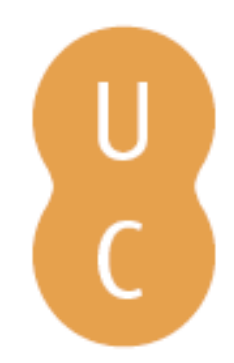



\section{O uso da fotografia na sala de aulas}
Autor(es):
Canelo, Maria José

Publicado por: Imprensa da Universidade de Coimbra

URL

persistente:

URI:http://hdl.handle.net/10316.2/35915

DOI:

DOl:http://dx.doi.org/10.14195/978-989-26-0690-3_5

Accessed : $\quad$ 26-Apr-2023 11:26:13

A navegação consulta e descarregamento dos títulos inseridos nas Bibliotecas Digitais UC Digitalis, UC Pombalina e UC Impactum, pressupõem a aceitação plena e sem reservas dos Termos e Condições de Uso destas Bibliotecas Digitais, disponíveis em https://digitalis.uc.pt/pt-pt/termos.

Conforme exposto nos referidos Termos e Condições de Uso, o descarregamento de títulos de acesso restrito requer uma licença válida de autorização devendo o utilizador aceder ao(s) documento(s) a partir de um endereço de IP da instituição detentora da supramencionada licença.

Ao utilizador é apenas permitido o descarregamento para uso pessoal, pelo que o emprego do(s) título(s) descarregado(s) para outro fim, designadamente comercial, carece de autorização do respetivo autor ou editor da obra.

Na medida em que todas as obras da UC Digitalis se encontram protegidas pelo Código do Direito de Autor e Direitos Conexos e demais legislação aplicável, toda a cópia, parcial ou total, deste documento, nos casos em que é legalmente admitida, deverá conter ou fazer-se acompanhar por este aviso. 


\section{O CRUZAMENTO DE SABERES NA AULA DE INGLÊS}

CONTRIBUTOS PARA UMA PRÁTICA MULTIDISCIPLINAR

ANA R. LUÍS COORD.

IMPRENSA DA UNIVERSIDADE DE COIMBRA COIMBRA UNIVERSITY PRESS 
Maria José Canelo

\section{Introdução}

Este texto reflete acerca do uso de fotografias na sala de aula, com base em trabalho realizado no âmbito de uma cadeira dedicada à cultura dos Estados Unidos da América durante o período específico da Grande Depressão e lecionada aos $2 .^{\circ}$ e $3 .^{\circ}$ anos da Licenciatura em Línguas Modernas. Este período histórico foi uma época particularmente produtiva em termos de fotografia, em parte devido aos grandes desastres sociais que marcaram a época, mas também pela própria estética fomentada pelo Governo de Franklin D. Roosevelt, através dos seus programas experimentais de apoio às artes. É neste contexto que é criado o Projeto de Fotografia da Farm Security Administration (FSA), que fez da Grande Depressão uma das épocas mais bem ilustradas da história dos E.U.A., criando fotografias que se tornaram perfeitos ícones da época. Esta reflexão toma então a fotografia como uma forma privilegiada de representação deste período histórico e cultural, um veículo de mediação do nosso acesso ao mundo e, por isso, um instrumento fundamental na construção de significado. As questões de análise cultural serão articuladas com outras, relacionadas com a própria natureza da fotografia, como, por exemplo, como é que a fotografia cria significado? Como é que ela orienta - e constrói - o nosso olhar? E, deste modo, como é que a fotografia pode enriquecer a análise cultural feita na sala de aulas? Partindo da ideia de que a fotografia constitui, em última análise, um discurso visual, este exercício questiona, num sentido produtivo, as formas como ela pode ser usada na sala de aulas, com que objetivos e que atividades poderão ser bem sucedidas em situações de ensino-aprendizagem. 


\section{A cultura na sala de aulas}

Entender o uso da fotografia implica, primeiro, perceber que objetivos, temáticos e pedagógicos, orientam a escolha deste instrumento de construção da realidade, no âmbito da disciplina lecionada. Mas antes disso, outro problema se coloca: a natureza da própria matéria - a cultura, objeto de muitas e diversas definições. É preciso perceber que cultura não é a mesma coisa que história, nem que literatura, por exemplo, embora a cultura se articule de muito perto com estas disciplinas. Por razões práticas, escolho, das várias definições, aquela que melhor responde aos meus objetivos científico-pedagógicos e também ao lugar que a Cultura Norte-Americana ocupa entre as outras cadeiras do plano de estudos de Línguas Modernas. Assim, atribuo à cultura a função de deslindar e comentar criticamente a criação de significado acerca da sociedade dos E.U.A.; o seu contributo para a criação de símbolos, valores, imagens, ideias, metáforas, todas elas portadoras de significados através dos quais as pessoas aprendem a orientar as suas ações e comportamentos, as suas formas de ver o mundo e o seu lugar no mundo. Um dos pensadores que mais me ajudou a articular o conceito de cultura foi o crítico marxista britânico Raymond Williams que, ao apresentar a cultura como um 'modo de vida', nos leva a entender como ela não se manifesta apenas como produto, nos artefactos que produzimos, como diziam as definições antropológicas tão influentes neste âmbito; com Williams aprendemos que a cultura já é anterior aos artefactos, informando as formas que eles tomam, porque informa já as representações e os moldes de pensamento de quem produz os artefactos. E assim a cultura é uma enorme rede simbólica em processo, que constrói representações e objetos materiais, refeitos e reciclados, numa dinâmica constante entre a subjetividade individual e o contexto histórico e social, o que permite aos sujeitos apreender os significados gerados, mas também contribuir para o próprio processo de (re-)significação. 


\section{A fotografia}

A fotografia é precisamente um destes produtos culturais, que tem o poder de gerar e manter em circulação uma série de significados através das representações do mundo que nos apresenta. Deste ponto de vista, faz sentido recorrer ao conceito de discurso e entender a fotografia como um discurso visual. A ideia de discurso deriva do entendimento de que o significado e a significação são criados na linguagem e através da linguagem. É nela que criamos as nossas representações do mundo e são estas que constituem os discursos. Assim, o discurso é um conjunto de formas de representação, convenções e hábitos de linguagem que produzem campos específicos de significados, que se situam cultural e historicamente (Brooker 2002:78).

Esta noção foi alargada pelo filósofo francês Michel Foucault, que chamou a atenção para a ligação do discurso com o poder, ou seja, que as nossas representações do mundo nos são largamente oferecidas como formas de conhecimento por instituições reguladoras, como a escola, a lei e os mídia. Estando estas associadas ao estabelecimento da ordem e da verdade, tendemos a usar representações simples - cómodas e ordeiras - para explicar o mundo. As subjetividades e as identidades (sexual - o que é o masculino, o que é o feminino, por exemplo; de classe, nacional, etc.) são exemplos deste tipo de representações. O mesmo se aplica a outros tipos de discurso, do documentário fílmico à animação, à música, ao romance, ou à poesia, qualquer deles passível de ser submetido a uma análise através da lente da cultura. No fundo, todos estes produtos culturais, nos quais os discursos circulam e os vão reproduzindo, funcionam como textos, na medida em que se constituem como sistemas de signos que se articulam no sentido de criar, articular e manter os significados. Por isso podemos 'ler' uma fotografia ou um filme, recorrendo a estratégias que usamos na literatura.

É esse tipo de análise, como leitura, que eu proponho. Mas, mesmo a partir daqui, outras questões ainda se nos impõem. Que fotografias escolher? Que fotógrafos? Quais se aplicam melhor a que tipos de matérias? E como explorar uma fotografia? E, antes disto tudo ainda, o que 
é uma fotografia? Uma seleção informada deve basear-se numa reflexão, mesmo que breve, acerca da fotografia, pois só uma consciência crítica acerca da fotografia como meio, e como veículo de representações, nos permite entender o seu potencial na sala de aulas enquanto discurso visual, para lá da mera imagem. Sabemos já que qualquer recurso visual na sala de aulas é uma mais-valia, pela capacidade que tem de mobilizar e prender a atenção do/as aluno/as, além de ser o tipo de registo que permanece mais tempo na memória. As imagens podem ser muito úteis como 'prompt', na ativação da aula, ou para descrição e ilustração de temas - mas, nestes casos, implicam sempre um prazo de atenção curto. Ao contrário, o registo escrito é uma boa forma de prolongar a atenção e consolidar o exercício - no caso da fotografia, ela tem a capacidade de despoletar uma história e assim criar significado.

Mas a primeira história a levar em conta, para o/a docente, é a da própria fotografia, porque só a partir daí poderá proceder a uma análise rigorosa de qualquer objeto deste tipo, na sala de aulas. A fotografia é herdeira direta da pintura e de uma ânsia de representação da realidade que está presente desde os primórdios da humanidade e tomou várias formas, no campo visual, ao longo dos séculos. 1822 inaugura uma nova forma de representação, precisamente a fotografia, que tem a sua etimologia no grego, significando pintar com luz, pela forma como usa o processo de projeção da luz. O processo original viria a ser desenvolvido por Louis Daguerre, que criou aquilo que ficou conhecido como o 'daguerreótipo'. Embora em parte a fotografia continue as tradições representacionais iniciadas pela pintura - a paisagem, a natureza morta, o retrato -, ela irá, gradualmente, afirmar uma identidade própria e, consequentemente, um espaço próprio. O seu aparecimento num contexto de perfeito delírio com o progresso e a evolução tecnológicas separa-a imediatamente das técnicas da pintura. Pois ainda que seja inicialmente aplaudida como a sua descendente direta, a fotografia é vista como essencialmente moderna: mais rápida, mais eficiente, mais autêntica e mais acessível.

O ambiente positivista do dealbar da fotografia é o mesmo que apoia o surgimento do realismo em várias formas de expressão, daí que este seja também uma das primeiras técnicas usadas na fotografia. A sua 
capacidade de reproduzir fielmente a realidade, de ser, afinal, a forma mais acabada até à data do ideal mimético, rapidamente a torna numa aliada fortíssima na construção da História. A fotografia logo é associada à ideia de documento, última prova de autenticidade dos factos; fidedigna, objetiva, neutra, cria-se o mito de que não pode mentir. A própria expressão 'tirar' uma fotografia, em vez de 'fazer' uma fotografia, nos dá conta da nossa crença de que a fotografia é uma função ou uma parte da realidade - embora só assim seja, porque as marcas da sua artificialidade não têm uma visibilidade imediata (Wells 1997:95).

Estas características acentuam-se se compararmos a fotografia a outro tipo de imagens profusamente usadas, por exemplo, nos jornais, na época em questão, como as gravuras e as caricaturas. Deste modo, a fotografia rapidamente adquire uma aura de autoridade associada à produção de significado, que não assistia aos desenhos ou às caricaturas. Como sugere Liz Wells, a fotografia confirmava ideias sobre o mundo que já tinham sido tratadas por outras formas culturais ou artísticas, mas a nova representação visual tornava as ideias mais reais e, sobretudo para a classe-média, a visualização era quase uma experiência real dessas ideias (1997:66). Daí também que a fotografia estabeleça outra aliança forte, desta vez, com a lei.

À medida que vai delineando este espaço próprio, a fotografia distancia-se, gradualmente, da pintura, assistindo este período ao desenvolvimento da fotografia como informação, que acompanhou o surgimento da consciência do direito a saber. O novo, e grande, objeto da fotografia vem a ser a realidade social. A máquina fotográfica deixa de querer apenas registar, para passar a expor, dando origem à metáfora da 'câmera com consciência' (cit. Clarke 145). Foi como se as fotografias começassem a falar: elas faziam uma revelação, ao mesmo tempo que transmitiam uma mensagem moral. De facto, a construção do pathos era uma componente fundamental da fotografia, nesta época.

Este percurso explica também como é que a fotografia se assume frequentemente como parte integral do trabalho de investigação sobre as condições de vida e de trabalho dos mais desfavorecidos. A fotografia passa a assumir juízos morais que orientam a recolha da realidade repre- 
sentada. São os primeiros passos a caminho de um género que desabrocharia no século XX, o documentário, que derivará também no fotojornalismo e na reportagem, mais tarde. Os casos dos fotógrafos Jacob Riis (1849-1914) e Lewis Hine (1874-1940), no contexto dos Estados Unidos durante o período do reformismo social, são paradigmáticos neste aspeto. A fotografia foi particularmente importante na divulgação das condições de vida e trabalho dos imigrantes. Jacob Riis trabalhou nos guetos (a princípio, como repórter criminal, com a polícia), especialmente o bairro de Lower East Side, em Nova Iorque, onde os imigrantes se amontoavam em exíguos apartamento alugados, os chamados 'tenements', nos bairros pobres da cidade, que ofereciam péssimas condições de higiene e salubridade. O seu trabalho culminou num estudo que ainda hoje é uma obra de referência histórica e social, How the Other Half Lives, publicado em Nova Iorque, em 1890. A fotografia de Lewis Hine seguiu-lhe as pisadas, obrigando a uma consciencialização não só pública mas também política dos perigos das condições de trabalho na época, conduzindo a avanços na legislação sobre o trabalho infantil, por exemplo, depois da sua divulgação em revistas, exposições públicas e posters. Este trabalho foi importante também porque, na época, a sociedade dos Estados Unidos separava radicalmente, inclusive em termos de espaço, a classe média das classes baixas. As pessoas abastadas dificilmente poderiam ter um conhecimento direto das condições de vida dos pobres - esse conhecimento chegou-lhes então através da fotografia (Levine 2004:60).

Contudo, esta ênfase no carácter mecânico e perfeitamente neutro da fotografia não dura para sempre. Gradualmente, os fotógrafos vão-se ressentindo dessa perspetiva puramente instrumental, bem como da sua associação ao mercado de massas, já que a fotografia surge justamente no contexto da democratização da cultura, da imagem como da própria tecnologia: a primeira máquina fotográfica de uso individual é colocada no mercado pela Kodak, em 1888, no mesmo cenário que assistiu à criação da escola pública e dos museus, por exemplo. Esta massificação levará os fotógrafos a procurar valorizar a fotografia de outras formas, nomeadamente realçando os seus atributos estéticos e o papel da criatividade do fotógrafo. 
Assim se cria uma outra consciência do processo fotográfico: a ideia de que a máquina fotográfica fornece factos objetivos dá gradualmente lugar à visão da fotografia como relato ou registo do mundo, no qual a verdade é construída através do poder do fotógrafo, um 'fazedor-de-imagens' que exerce necessariamente uma observação criativa sobre a realidade. Por consequência, a autenticidade deixa se ser tão associada ao processo técnico, passando antes a depender mais de qualidades pessoais e das práticas profissionais do fotógrafo, o que cria condições para associar autenticidade a originalidade, mais do que a genuinidade. A mais ou menos longo prazo, a canonização de alguns fotógrafos como artistas e o estabelecimento da fotografia como arte consolidaria esse processo.

\section{A leitura da fotografia}

Este pré-conhecimento da evolução da fotografia, da sua afirmação social e cultural, das funções que foi desempenhando e das condições da sua receção deve estar presente quando selecionamos uma dada fotografia e também quando a analisamos na sala de aulas, bem como nas orientações e sugestões de leitura que proporcionamos ao/as aluno/as.

Devemos ter também em mente que a forma como vemos as coisas é condicionada pelo que sabemos; que quem somos e onde nos situamos influi sobre a forma como percebemos a realidade. Porém, a nossa capacidade visual é mais imediata que a de elaboração mental e reprodução por palavras; vemos antes de falar - e aquilo que vimos pode bem ser diferente daquilo que sabemos. Isto para dizer que ver é um processo ativo, por um lado, e subjetivo, por outro e que estes são dois fatores complementares no ato de ver. Por isso também, o significado que atribuímos (e não que 'encontramos') nas imagens é, por norma, instável. Contudo, um espetador informado fará sempre uma activação mais rica do seu olhar, pela forma como contextualiza a imagem através da informação ou do conhecimento que já possui.

Para além disso, é comum que a imagem adquira autonomia; que se torne uma realidade em si mesma - como um ícone de uma determinada 
época, de um tipo social, de uma ideia. Embora comece por se articular com o original que representa, ela pode vir a conquistar um significado para lá dessa ligação. A gravura do rosto de Che Guevara, a preto, sobre um fundo vermelho, por exemplo, significa muito mais do que a representação do sujeito histórico ou individual. Mas, apesar dessa capacidade de autonomia, a imagem não aparece sozinha, naturalmente. Há sempre um olho humano por detrás da máquina; há sempre intenções, desejo, motivação pessoal guiando a captação do momento. A crítica cultural norte-americana Susan Sontag sintetizou de forma bastante útil aquilo a que poderíamos chamar os usos da fotografia: a fotografia é um ritual social (no registo de ocasiões como um casamento ou um batizado); é também uma defesa contra a ansiedade (dando-nos a ideia de propriedade contra o medo da perda, quer se trate do passado, no caso do envelhecimento, ou de espaços desconhecidos, como a fotografia do turista); e, last but not least, a fotografia é sempre um instrumento de poder. Aqui, Sontag sublinha algo de que nos esquecemos frequentemente: o aspeto predatório da fotografia e a assimetria de poder que lhe subjaz. A fotografia tem a capacidade de representar sujeitos de modos que eles próprios não escolhem nem podem ver, tornando-os em objetos que podem ser possuídos simbolicamente pelos espetadores - um processo a que já se chamou o espetáculo do Outro. Ou seja, retira ao retratado o poder sobre a sua própria imagem, ao mesmo tempo que este processo expõe a complexidade do próprio olhar do espetador, que, na verdade, apenas na aparência é um ato simples.

Há, pois, uma série de componentes a ter em mente, na observação e leitura de uma fotografia: em primeiro lugar, tirar uma foto é selecionar uma foto. Quem tira, em que espaço e com que intenções são peças relevantes na leitura. Tal como importa a coisa em si, o objeto fotografado: os detalhes, a moldura, a pose do retratado, bem como o olhar do sujeito frente à câmera; importa igualmente a perspetiva do fotógrafo, tal como outros elementos que contribuem para a composição, como estratégias visuais, nas quais podemos incluir elementos tão básicos quanto o uso da cor ou da luz. Para além desses elementos, que afetam as estratégias de representação, não devemos deixar de procurar as perguntas que a imagem nos coloca. 


\section{Contextualização do caso da aula de Cultura Norte-Americana}

A Cultura Norte-Americana 2 é uma cadeira semestral, que foi projetada como temática, abordando o período específico da Grande Depressão, na década de 30 do século XX. São na verdade de natureza diversificada os materiais que uso na abordagem do tema, desde discursos do Presidente Roosevelt (em texto e radiofónicos), a posters da Works Progress Administration; documentários de animação da Disney, ou fílmicos, do realizador Pare Lorentz; baladas de Woody Guthrie; poemas de Muriel Ruckeyser, ou narrativa curta, por exemplo, o romance Yonnondio. From the Thirties, da escritora Tillie Olsen. As fotografias da FSA têm no entanto uma componente visual particularmente forte, até porque em alguns casos o/as aluno/as já as conhecem.

A escolha do período da Grande Depressão deve-se ao facto de, no meu entender, ele permitir uma abordagem da cultura dos Estados Unidos perfeitamente fora dos estereótipos e clichés ligados ao mito do Sonho Americano - e dos Estados Unidos/ 'América' hegemónica que, a meu ver, devem ser questionados, confrontados e complementados com outras histórias e perspetivas. A Depressão é precisamente uma época em que a 'América' mítica está completamente do avesso e há que encontrar alternativas, não só para resolver a crise e as contradições do mito, mas também para representar e entender essa outra 'América' que contradiz o mito, para a qual não há representações e fórmulas feitas. O programa socioeconómico lançado na altura por Roosevelt, o chamado New Deal, é uma alternativa; uma resposta à crise económica avassaladora que, deixando cerca de onze milhões da população ativa no desemprego, cancelava completamente o modelo capitalista consumista que estava na base do próprio American Way of Life e todas as outras promessas a ele subjacentes. Era também uma situação de potencial desordem, que catalisava perigosamente ideologias consideradas anti-americanas, como o socialismo e o comunismo, por isso exigia uma atenção permanente aos problemas sociais e aos conflitos. Os grandes desastres ecológicos da década só agravaram mais ainda esta situação. Foi neste contexto que o New Deal de Roosevelt se aventurou, também com políticas culturais novas, baseadas 
na ideia da democratização da cultura, e assim esboçando uma nova relação entre o Estado, o artista e o cidadão. O New Deal cria agências e financia projetos artísticos variadíssimos para devolver o trabalho a um elevado número de desempregados ligados às artes e às indústrias do entretenimento.

É neste âmbito que se desenvolve o documentário como género, que vem a ser particularmente influente na fotografia. Embora a matéria de trabalho continue a ser a realidade, e o método, uma tradição realista, os fotógrafos documentais do New Deal recorrem a estratégias visuais próprias, inventando, com as suas imagens, uma sintaxe coerente para uma nova linguagem, ou novas formas de representação para dizer e significar a América da Depressão. Ao mero registo e exposição do real, a câmera fúlmica, como a fotográfica, acrescentaram uma consciência, produzindo 'fotos que falam' e assim interpelam o observador e as suas emoções, como nos é dito por William Stott, num dos primeiros estudos de referência do género, Documentary Expression and Thirties America (1986).

A relação destes artistas com os projetos estatais é, no entanto, problemática, como já referi, inserindo nas fotografias elementos ambíguos que nos demonstram como, afinal, as fotografias podem manipular a realidade; no entanto, é também este aspeto que pode tornar a discussão na aula mais produtiva. Proponho pois que nos debrucemos sobre alguns exemplos de fotógrafos FSA entretanto canonizados, Dorothea Lange (1895-1965) e Margaret Bourke-White (1904-1971), apenas dois exemplos de uma longa lista.

\section{Algumas sugestões de leitura de fotografias da Farm Security Administration}

Para uma abordagem mais rigorosa das fotografias, há que fornecer ao/às aluno/as alguns dados materiais da sua produção e também da receção das fotos na época: não apenas no tocante ao contexto sociocultural e histórico da Depressão, mas das próprias condições de produção e objetivos do projeto muito concreto em que estão inseridas, a 
cargo da FSA, que era uma Secção do Ministério da Agricultura. Com efeito, as fotografias foram concebidas ao abrigo de uma campanha de relações públicas do Governo, que pretendia divulgar e justificar a sua ação contra os grandes problemas que assolavam a nação. Era uma campanha clara de propaganda e consciencialização da população, que visava, como foi declarado na altura, 'apresentar a América aos americanos', uma América com um rosto humano e humanizador - de acordo com o discurso oficial.

As fotografias tiradas no âmbito do projeto destinavam-se a constituir um arquivo na FSA, ao qual tanto as pesquisas sociais da agência, como as grandes revistas e jornais, podiam recorrer, na recolha de material visual para ilustrar textos e reportagens. O público-alvo era a população urbana da classe média, que normalmente comprava jornais e revistas. O legado desse empreendimento é cerca de 75.000 negativos e mais de 170.000 fotografias, na sua maioria hoje disponíveis ao público, através da Biblioteca do Congresso, o que certamente também contribuiu para um impacto e popularidade tão duradouros.

Em termos práticos, o/as fotógrafo/as deslocavam-se às áreas críticas com instruções para coligir factos visuais, registando situações que correspondessem ao discurso do Governo sobre a pobreza e o desemprego: na 'América' da Grande Depressão, as pessoas eram verdadeiramente pobres e verdadeiramente dignas e essa genuinidade acabava por as salvar moralmente da miséria. Como o Presidente Roosevelt afirmara no seu primeiro discurso de tomada de posse, em 1933, em tempo de crise os valores materiais tinham de ser substituídos por valores espirituais - e as fotografias acabariam por funcionar, deste modo, como um discurso visual no âmbito destas representações do discurso oficial, embora a subjetividade de cada fotógrafo/a explique como cada um/a conseguiu responder às exigências do seu trabalho, criando também um discurso visual individual. A tensão entre a propaganda e a individualidade de cada fotógrafo/a constitui um dos aspetos mais interessantes do projeto.

Assim, tendo em mente os preceitos teóricos sobre a fotografia expostos acima, e com a informação que transmitimos ao/às aluno/as de contex- 
tualização específica do Projeto de Fotografia da FSA, oriento a leitura das fotografias no sentido de percebermos até que ponto as instruções da FSA ao/às fotógrafo/as têm uma tradução clara nas fotografias, ou se, pelo contrário, estas se desviam das ordens oficiais e oferecem a possibilidade de outras leituras - isto é, como é que elas funcionam como discurso visual. Voltando à primeira parte deste texto, a pergunta primeira que deve nortear a exploração da imagem deve ser: como é que esta fotografia cria significado? De que estratégias de composição visual se vale? Que efeitos consegue, que expliquem a popularidade que de facto atingiram entre o público da época? Em suma: que trabalho cultural desempenha esta fotografia? É neste ponto que é fundamental ao/à professor/a, que orienta o exercício, retomar a ideia do potencial da fotografia enquanto discurso visual.

O exercício torna-se mais produtivo ainda se a parte descritiva da imagem, que funciona bem como discussão em grupo, um exercício meramente oral, tiver como 'follow-up' um exercício escrito de carácter mais livre de composição de uma narrativa, por exemplo. A discussão permite saber mais acerca da fotografia - onde foi tirada e em que circunstâncias ou com que funções, quem são as pessoas/figuras fotografadas, que laços há entre elas, a idade, a ocupação, etc., informação que pode ser fornecida ao/às aluno/as, encorajando-o/as a colocar ele/as próprio/as perguntas à fotografia. Como material de apoio, complementar a este exercício, sugiro uma seleção de dois ou três textos originais da época, que podem ser encontrados na obra Hard Times. An Oral History of the Great Depression (1986), uma compilação de história oral, que guarda testemunhos da época: entrevistas a homens e mulheres, de variadas classes, idades e etnias, que viveram a Grande Depressão, conduzidas e reunidas em volume pelo historiador Studs Terkel. São narrativas curtas e num registo oral, informal e direto, por isso de leitura acessível.

Esta atividade permite que o/as aluno/as possam expressar, por um lado, o seu acompanhamento da matéria, contextualizando a imagem, enquanto, por outro, podem aplicar os conhecimentos através de um exercício mais criativo, que lhes permite pôr em prática a sua própria sub- 
jetividade. Por fim, e dada a 'mensagem manifesta' que é o selo de marca destas fotografias, um exercício livre deste tipo oferece ao/às aluno/as a oportunidade de serem crítico/as em relação à imagem, seguindo ou desafiando a 'mensagem', mas, em todo o caso, usando um 'olhar ativo', em vez de contemplarem/consumirem passivamente as imagens.

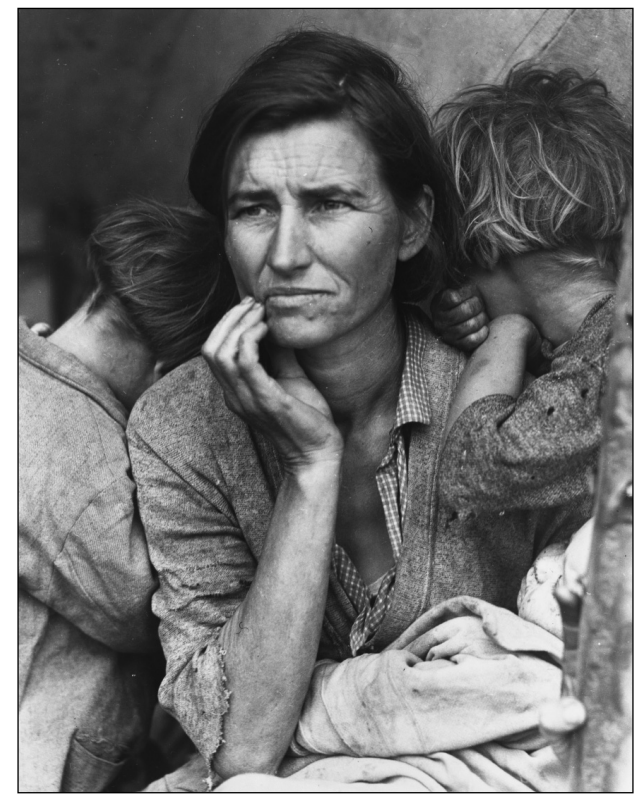

A. Dorothea Lange, "Migrant Mother" (1936)

Esta fotografia foi tirada na Califórnia, para onde se dirigiram muitos dos desalojados das Grandes Planícies, em virtude do fenómeno do Dust Bowl, depois de anos a fio de cultivo intensivo terem tornado a terra estéril. A imagem tornou-se num ícone da Grande Depressão, sob diversos aspetos: dos trabalhadores rurais; da maternidade vergada às circunstâncias da época, e da própria ética e estética subjacentes ao trabalho de fotografia promovido pela FSA. Muita da sua força reside na intensidade emocional que a imagem desperta e que depende também da composição perfeita da moldura que as três crianças traçam ao redor da mulher, que simultaneamente dela faz, perfeitamente colocada 
no seu centro, o pilar da família. Esta centralidade da figura maternal é, todavia, colocada em causa pela preocupação estampada no olhar da mulher-mãe-trabalhadora, perdido num horizonte que só podemos imaginar. O trabalho, ausente do retrato, está, no entanto, implícito, porque da imagem está ausente também a figura do homem-pai, o ganha-pão tradicional. Isto reforça o peso da mãe, cujo papel na família vai muito além do mero sustento emocional. A força emocional da fotografia deriva do efeito do olhar, que assinala precisamente a acumulação de responsabilidades desta mulher; a falta do sustento material compromete também o sustento emocional. Se o horizonte é metáfora do futuro, o que quer que ela procura vislumbrar no olhar perdido pode estar, como esse olhar, perdido também.

"Migrant Mother" faz parte de um conjunto de fotografias que recontextualizam na Grande Depressão uma tradição fotográfica herdada da pintura, o retrato. Embora um dos aspetos mais relevantes da democratização da fotografia tenha sido, justamente, a possibilidade de imortalização de qualquer pessoa (e não só dos nobres e, depois, dos burgueses, como até ao século XIX) através do registo fotográfico, o retrato consegue manter a ideia de enobrecimento do sujeito representado, que contribui muito, no caso da fotografia de Lange, para o significado que a fotografia procura construir. A importância e valor associados a essa tradição são assim transpostos para os retratados, nas fotografias da FSA. Este aspeto sublinha a dignidade e o heroísmo destas pessoas comuns, que se mantêm responsáveis perante a adversidade, numa celebração do persistente espírito de sobrevivência destes homens e mulheres (- e digo assim, porque a fotografia os humaniza, embora não individualize), que, no anonimato das fotografias, representam todo o povo dos Estados Unidos. Trata-se, pois de uma fotografia ordeira na composição, com a sua moldura humana rígida e harmoniosa, como ordeira na mensagem: independentemente das calamidades que afetassem a 'América', não há lugar para a derrota nem o desespero, nem para a rebeldia e a desordem, enquanto o espírito do povo for altivo e digno. 


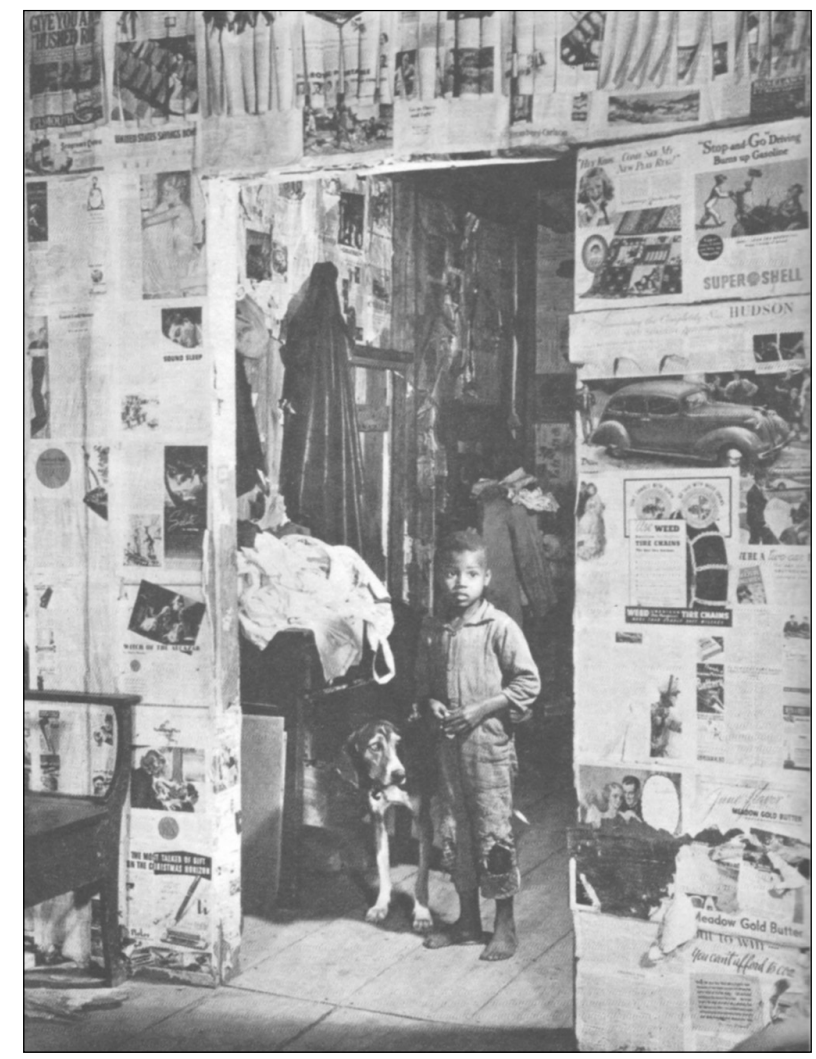

EAST FELICIANA PARISH, LOUISIANA.

"Blackie ain't good for nothing, he's just an old hound dog" B. Margaret Bourke-White, "Sharecropper's Home" (1937)

Tirada no Sul dos Estados Unidos, onde grande parte dos descendentes de escravos e ex-escravos afro-americanos nunca tinham tido acesso ao 'Sonho Americano' apesar de a Emancipação levar já setenta anos, esta fotografia de Bourke-White demonstra como, no Sul e para os afro-americanos, a Depressão não era um momento, mas um modo de vida. Os detalhes e a composição da imagem - a desordem da barraca, as roupas rasgadas, a criança descalça -, evidenciam uma pobreza anterior à Depressão. Rodeando a criança, observamos um mundo de textos visuais, cujo significado é imediato: os jornais, pejados de anúncios publicitários que prometem os elementos fundamentais da América do consumo 
enquanto versão do "American Dream" na época. Mas o contraste é que sobressai: da promessa da publicidade, a criança partilha os farrapos e o lixo, porque, na verdade, o "American Dream" é branco - basta examinar com cuidado as gravuras e fotos dos jornais e apercebemo-nos de que todas, sem exceção, são de brancos. No Sul, era comum os trabalhadores rurais usarem jornais como isolamento das paredes das barracas de madeira, mas, nesta fotografia, o contraste explícito entre a criança, ao centro, e a moldura de jornais, cria uma significação política. O contraste sinaliza uma série de questões que alargam o tema da fotografia: esta representação da pobreza faz-nos pensar na injustiça e nas desigualdades sociais - questões que se nos impõem também pelo olhar direto da criança, que apela ao sentimento do observador.

O sentimental é um elemento significativo do discurso visual das fotografias de Bourke-White neste período (note-se como a mulher, na fotografia de Lange, evita o olhar do observador), como se pode ver logo no título de uma obra que publica, em 1937, com o também fotógrafo Erskine Caldwell e que é uma das referências da estética fotográfica da FSA, You Have Seen Their Faces. O sentimental revela-se também no uso de títulos sob as imagens: "Blackie ain't good for nothing, he's just an old hound dog”, lê-se por baixo da fotografia, exatamente como uma legenda. Este aspeto torna a leitura mais guiada, pois acresce ao significado da fotografia, reforçando a ideia da injustiça social: 'Blackie' refere-se ao cão, que já não serve para nada, de velho, mas bem se podia aplicar também à criança (pelo diminutivo do nome) por ser negra. Esta ideia de os negros não servirem para nada, marca do racismo no Sul dos E.U.A. e não só, era outra maneira de dizer que não havia lugar para eles na sociedade norte-americana. Era a linguagem do preconceito, inerente à cor da pele. Um dos maiores feitos do Projeto de Fotografia desta agência governamental, ao instalar de forma generalizada o tema da pobreza, foi permitir relembrar às autoridades e ao grande público que os negros continuavam enredados nessa realidade.

Estas duas fotografias, apesar de diferentes no estilo, são ambas de registo simples, dramáticas e acessíveis. A ambiguidade de que vive a construção de significado, na primeira e o contraste que é a base do pro- 
cesso de significação, na segunda, não tornam a leitura da imagem mais difícil. Para o dramatismo concorrem, além do uso do preto e branco, o recurso a temas plenos de pathos na cultura ocidental, a maternidade, as crianças, a miséria e a pobreza, embora a representação de Lange seja mais contida e, portanto, oriente menos o observador.

O projeto fotográfico da FSA tem feito correr muita tinta por parte da crítica, também da dos estudiosos de fotografia. A questão da esteticização da pobreza, não só no efeito da composição, que acaba por resultar numa imagem bela, como os próprios valores atribuídos ao povo dos E.U.A. - a coragem e a confiança e a dignidade como resposta ao sofrimento - sugerem uma outra beleza sob a superfície da pobreza, que acaba por ser problemática, embora, naturalmente, se articule bem com o discurso oficial que as gerou. Acreditamos nós, como observadores, nessa beleza? Ou conseguimos resistir às estratégias que nos convidam à contemplação e conseguimos ativar um olhar crítico, no sentido de nos apercebemos da predatoriedade deste projeto fotográfico, seguindo a crítica de Susan Sontag, ao deixar aquelas pessoas e as suas vidas à mercê do nosso olhar e dos nossos juízos? Não serão a mãe, na imagem de Lange, e o rapaz, na de Bourke-White, apropriados por molduras simbólicas escolhidas e estabelecidas pelas fotógrafas? As figuras, anónimas e silenciosas, sendo privadas do seu próprio testemunho da situação que alegadamente representam, que seria articulado no seu discurso individual e subjetivo? Não acabarão elas por ser transformadas em símbolos passivos e intemporais da pobreza? Mas, por outro lado, urge perguntar também (não só em relação a estas duas fotografias, mas levando em conta a vasta galeria de retratos dos destituídos da Grande Depressão), por que é que estes sujeitos se deixaram fotografar e chegavam a ensaiar poses para a câmera?

No exercício de composição escrita que proponho, como atividade mais ou menos dirigida, é pedido ao/às aluno/as que escrevam uma história a partir da fotografia. O texto deve incluir informação sobre o contexto sociocultural e histórico como o meio em que as figuras se movem; mas, noutros contextos de ensino, nomeadamente a nível do ensino secundário, a mesma análise detalhada da fotografia pode ser propícia a 
outro tipo de exercícios: criação de diálogos, descrição do pensamento das figuras, fazer uma análise do carácter sugerido a partir de elementos da imagem, eventuais relações entre as figuras ou a criação de um enredo que é a sua história de vida, inspirada pelo momento que a fotografia regista. Embora a discussão que antecede esta atividade forneça muita informação contextual, inclusive sobre as próprias condições materiais de produção destas fotografias, a escrita é sempre criativa, porque há muito que suplementar com a imaginação do/a aluno/a. Note-se também que a ambiguidade das imagens é sempre produtiva, na medida em que, tornando embora o exercício mais exigente, liberta a interpretação e, portanto, enriquece a escrita.

Na sequência desta atividade, e de modo a complementar o estudo da matéria, pode ser pedido ao/às aluno/as trabalho de pesquisa, para criação de um pequeno arquivo com imagens semelhantes, do mesmo período, mas, desta vez, de acordo com os seus próprios critérios de seleção. Podem ser fotografias semelhantes às discutidas na aula - o tema das representações de maternidade, por exemplo, era um dos preferidos do/as fotógrafo/as da época, não só de Dorothea Lange. Este trabalho é, aliás, relativamente fácil, já que os arquivos da FSA foram depositados na Biblioteca do Congresso e estão hoje abertos ao público, encontrando-se acessíveis através da internet. Outros exercícios possíveis na didatização deste tipo de material incluem o corte da imagem, com isolamento de detalhes, a combinação de várias imagens ou a comparação e contraste de duas fotografias, bem como a proposta de legendagem.

Outros fotógrafos norte-americanos cuja obra pode ser produtiva nas aulas de Inglês, como complemento à abordagem sugerida nos manuais de ensino, são Adam Clark Vroman (1856-1916), cuja galeria de retratos de índios-nativos de territórios vários dos EUA se afasta bastante do cânone, ao humanizá-los e assim recusa a perspetiva romântica tradicional; Ansel Adams (1902-1984), que tem excelentes fotografias para discutir temas de ecologia e Robert Frank (1934-), sobretudo na sua obra The Americans (publicada em 1959), para explorar e discutir os E.U.A. da década de 1950, designadamente aspetos problemáticos da sociedade de consumo. 


\section{Considerações finais}

Para finalizar, creio que uma abordagem deste tipo permite ao/às aluno/ as aprender mais sobre a própria natureza do objeto fotográfico, a sua margem de imitação da realidade a par do seu contributo para a construção dessa mesma realidade - ou seja, a fotografia como representação -, uma vez que torna o/a aluno/a num/a observador/a criativo/a, colocando-o/a na pele do fotógrafo, por assim dizer. Esta conclusão importa, porque cria no/a aluno/a uma perceção crítica em relação à miríade de representações visuais da realidade com as quais se cruza diariamente.

\section{Referências}

BroOKer, P. 2002. A Glossary of Cultural Theory. New York: Oxford University Press. Caldwell, E. e M. Bourke-White. 1995. You Have Seen Their Faces. Athens, Georgia: The University of Georgia Press. [1937].

Clarke, G. 1997. The Photograph. New York: Oxford University Press.

DAvis, K. 1995. The Photographs of Dorothea Lange. Kansas City, Mo.: Hallmark Cards.

La Grange, A. 2008. Basic Critical Theory for Photographers. Oxford: Focal Press. Lange, D. 1994. American Photographs. San Francisco: Chronicle Books.

LEVIne, R. M. 2004. Insights into American History. Photographs as Documents. Upper Saddle River, NJ: Pearson/Prentice Hall.

RIIS, J. 1971. How the Other Half Lives: studies among the tenements of New York. New York: Dover Publications. [1890].

Roosevelt, F. D. 2000. First Inaugural Address. In R. Polenberg. The Era of Franklin D. Roosevelt 1933-1945. A Brief History with Documents. Boston: Bedford/ St. Martin's, 40-44.

Sontag, S. 2008. On Photography. In A. la Grange. Basic Critical Theory for Photographers. Oxford: Focal Press, 30-66.

STотт, W. 1986. Documentary Expression and Thirties America. Chicago: Chicago University Press. 
Terkel, S. 1986. Hard Times. An Oral History of the Great Depression. New York: The New Press.

Wells, L. (Ed.). 1997. Photography: A Critical Introduction. London: Routledge.

Williams, R. 1997. Culture is Ordinary. In A. Gray e J. McGuigan. (Eds.). Studying Culture. An Introductory Reader. London: Arnold, 5-14. [1958]. 